\title{
ASOINCA:
}

\section{un sindicato docente con propuesta pedagógica}

ASOINCA:

A Teachers' Union with

Pedagogical Proposal
ASOINCA: um sindicato de

professores com proposta

pedagógica
Alcira Aguilera Morales* https://orcid.org/0000-0002-3167-1777

María Isabel González Terreros** https://orcid.org/0000-0001-5543-7937

\section{Para citar este artículo}

Aguilera-Morales, J. C. y González-Terreros, M. I. (2022). ASOINCA: un sindicato docente con propuesta pedagógica. Folios, (55). https://doi.org/ 10.17227/folios.55-11493

Artículo recibido $19 \cdot 03 \cdot 2021$

Artículo aprobado $02 \cdot 07 \cdot 2021$

Latinoamericanos por la Universidad Nacional Autónoma de México (UNAM).

Correo: aamorales@pedagogica.edu.co.

** Profesora de la Universidad Pedagógica Nacional y doctora en Estudios Latinoamericanos por la Universidad Nacional Autónoma de México (UNAm).

Correo: migonzalez@pedagogica.edu.co 


\section{Resumen}

Este artículo de investigación explora una de las facetas menos abordada en el sindicalismo magisterial, la cual es aquella asociada a su identidad pedagógica. En ese sentido, queremos mostrar que, pese a la crisis del sindicalismo y en particular del magisterial, algunos sindicatos, como en el caso de la Asociación de Institutores y Trabajadores de la Educación del Cauca (ASoInCA) en Colombia, vienen realizando apuestas pedagógico-políticas que contribuyen al fortalecimiento de los maestros, de las escuelas y del sindicato en particular. Los grupos sindicales se constituyen, entonces, en movilizaciones sociales por la educación que se vinculan y van más allá de las reivindicaciones gremiales propias del sindicalismo en general, posibilitando afianzar una relación identitaria con una postura político-pedagógica de la labor docente.

\section{Palabras clave}

sindicalismo magisterial; experiencias político-pedagógicas;

soberanía alimentaria; ASOINCA; educación popular

\section{Abstract}

This research article explores one of the least addressed facets of teachers' unionism, which is associated with its pedagogical identity. In this sense, we want to show that despite the crisis of unionism and in particular of the teachers' union, some unions like the Association of Teachers and Education Workers of Cauca (ASOINCA) in Colombia, have been making pedagogical-political bets that contribute to the strengthening of teachers, schools and the union in particular. The union groups constitute social mobilizations for education, linked to and go beyond the union demands of trade unionism in general, making it possible to strengthen an identity relationship with a political-pedagogical position of the teaching work.

Keywords

teacher unionism; pedagogical and political experiences; food sovereignty; ASOINCA; popular education

\section{Resumo}

Este artigo de pesquisa explora uma das facetas menos abordadas do sindicalismo docente, a qual é aquela associada à sua identidade pedagógica. Nesse sentido, queremos mostrar que, apesar da crise do sindicalismo e em particular da profissão docente, alguns sindicatos, como é o caso da Associação de Instituições e Trabalhadores da Educação de Cauca (ASoINCA) na Colômbia, têm feito apostas pedagógico-políticas que contribuem para o fortalecimento dos professores, das escolas e do sindicato em particular. Os grupos sindic ais constituem-se então em mobilizações sociais pela educação que se vinculam e vão além das reivindicações gremiais próprias do sindicalismo em geral, possibilitando afiançar uma relação de identidade com um posicionamento político-pedagógico do trabalho docente.

\section{Palavras chave}

sindicalismo docente; experiências político-pedagógicas; soberania alimentar; AsoıncA; educação popular 


\section{Introducción}

El presente artículo forma parte de la investigación "Experiencias pedagógicas para tramitar el conflicto en contextos de guerra. Propuestas desde los sindicatos magisteriales", ${ }^{1}$ realizada con apoyo del Centro de Investigaciones de la Universidad Pedagógica Nacional, y que tuvo como objetivo aproximarse al sindicalismo magisterial para explorar sus apuestas pedagógico-políticas, especialmente de las experiencias que gestan los maestros sindicalizados para afrontar el conflicto armado colombiano. Aquí queremos presentar nuestra búsqueda acerca del papel de los sindicatos docentes en torno a la producción $\mathrm{y}$ defensa de posturas pedagógicas.

La lucha reivindicativa-gremial ha sido el interés histórico de las investigaciones y una de las razones más fuertes por las que se afilian los trabajadores a los sindicatos en el continente. La lucha gremial que ha dado el sindicalismo por alcanzar cierta estabilidad para sus trabajadores buscando mantener los derechos adquiridos o lograr nuevos, así como la consolidación de cooperativas gremiales que ofrecen posibilidades de crédito y ahorro han sido razones

1 La investigación la realizaron María Isabel González Terreros, Alcira Aguilera Morales, Víctor Manuel Rodríguez y Alfonso Torres Carrillo, profesores investigadores de la Universidad Pedagógica Nacional de Colombia. importantes para que los trabajadores ingresen a los sindicatos. La mayor parte de las investigaciones sobre el sindicalismo magisterial en América Latina muestran las movilizaciones en defensa de la educación pública, las reivindicaciones laborales-salariales, las tensiones político-ideológicas, y las lucha contra las políticas educativas y sociales de corte neoliberal.

Precisamente, en las revisiones bibliográficas encontramos que una veta poco identificada es el lugar que tiene la acción pedagógica del docente en el sindicalismo. Algunos autores, como LoyoBrambila (2008) y Tiramonti (2001), enuncian el escaso grado de desarrollo de este tema, tal vez, debido a la supeditación del campo pedagógico a la lucha sindical. Entonces, el abordar esta veta, amplía la mirada acerca del sindicalismo magisterial, pues se sale de los lugares comunes y se ubica en la recuperación de los conocimientos, saberes y prácticas pedagógicas que han construido las organizaciones gremiales docentes y que contribuyen a comprender parte de la identidad del sindicalismo magisterial.

En ese sentido, exploramos la manera como la Asociación de Institutores y Trabajadores de la Educación del Cauca (AsorncA), un sindicato magisterial que acoge a docentes y trabajares de la educación en ese departamento, incide en la práctica 
educativa de sus afiliados, y en las comunidades donde ellos trabajan. Esta veta muestra otras acciones del sindicalismo magisterial, pues varias de sus prácticas políticas están situadas en las apuestas formativas para potenciar las experticias educativas de los maestros afiliados.

Para abordar este aspecto, retomamos a Aurora Loyo (2008), quien encuentra dos lógicas en la acción magisterial: la gremial y la profesional, es decir una intersección entre el campo político (gremial) y el de la educación (profesional), de modo que estas dos lógicas atienden a su identidad como organizaciones docentes. De allí que la autora ubique al Movimiento Pedagógico Colombiano de la década de los ochenta como el intento magisterial más serio en la reconstrucción de un discurso fundado en un conocimiento sistemático del educador y la recuperación de su protagonismo en la construcción de alternativas para la educación.

Ello indica que comprender la lucha docente desde una perspectiva reivindicativa y gremial puede desconocer su campo profesional y su aporte a la formación docente como atributo central para pensar la identidad del sindicalismo magisterial. La acción sindical ha estado activa en contra de las reformas educativas que se agencian a lo largo del continente en los últimos años, por lo que es necesario ampliar las miradas e integrar aquellas luchas y movilizaciones que permitan identificar "la manera en la que los maestros se organizan en tanto gremio [que] incide en la gestión escolar" (Loyo, 2008, p. 346), es decir, como gremio profesional de la educación, que se diferencia de otros sindicatos porque está compuesto por docentes que forman ciudadanos, y tiene un saber pedagógico y un campo de acción: la escuela.

Esta veta es muy importante para el sindicalismo, pues le provee identidad colectiva y fortalece el quehacer profesional de los maestros. Por esto, nos arriesgamos en el ejercicio de buscar las prácticas y conocimientos pedagógicos creados y recreados por ASOINCA, un sindicato que ha estado configurando una apuesta política y pedagógica a partir de la educación popular. Para ello, se recurrió a la metodología participativa de corte sociocrítico, que permite realizar un trabajo de campo en interacción con los sujetos que viven la experiencia, pero no para observarlos, sino para construir colectivamente. ${ }^{2}$

Este artículo está estructurado en tres apartados: en el primero mostramos un marco general acerca del origen de los sindicatos magisteriales y de las movilizaciones sociales, que ha sido la forma como se visibilizan en América Latina. En el segundo apartado, nos adentramos en las características de ASOINCA, sobre todo en su "economía popular", como práctica educativa de formación y de organización; por último, en el tercer momento presentamos las experiencias pedagógicas del sindicato como parte de su apuesta político-pedagógica. Así, en las conclusiones abordaremos algunos rasgos distintivos de su identidad como gremio profesional que se está construyendo desde la educación popular.

\section{El sindicalismo magisterial en la esfera pública}

En la región latinoamericana existen diferencias en torno a la configuración del sindicalismo magisterial. Para el caso de Colombia y otros países, el hecho de tener una permanencia de Estados oligárquicos a principios de siglo $\mathrm{xx}$, junto con un tipo de producción económica basada en la agricultura, llevó a la no incorporación de "nuevos sectores sociales al mercado de empleo formal y a la participación política y social hasta avanzado el siglo xx" (Tiramonti, 2001, p. 26). Es decir, la población empobrecida se mantuvo vinculada al sector primario de la economía, por lo que no se constituyó en una clase emergente que ingresara a la educación; por ende, el crecimiento de la educación formal y el cuerpo docente durante la primera mitad del siglo $\mathrm{xx}$ no fue significativo.

Sin embargo, sobre todo después de la segunda mitad del siglo xx y producto del desarrollo industrial, comenzó a emerger un sector social ligado a la industria, con una clara influencia sociopolítica y económica en sus respectivos países y regiones. Estos sectores emergentes justificaron su ascenso social, no solo a través de su economía, sino que

2 Para profundizar en la metodología, véase González Terreros et al. (2014). 
buscaron en la educación una forma de legitimación de tal ascenso, y también comenzaron a influir en las políticas y partidos políticos que dirigían el Estado. Así, "El acceso a la educación pública se constituyó desde un principio en una estrategia de estos sectores para asegurarse y consolidar su movimiento ascendente. La ampliación de las matrículas de educación pública es una constante en este período" (Tiramonti, 2001, p. 6). Este ascenso social desencadenó unas dinámicas sociales internas distintas, y esta clase emergente entró a ganar un lugar en los espacios de poder tradicional y a plantear demandas sociales a los partidos, que se vieron obligados a incluirlos en la dinámica política.

Tal como lo desarrolla Tiramonti (2001), en todos los países de la región, a diferencia de lo acontecido en Europa, el Estado o los propios partidos políticos son los artífices de la constitución de un sistema sindical. De acuerdo con la autora, la aparición del sindicalismo docente estuvo asociado a aquellos países de modernización temprana, identificados con un modelo económico benefactor, que incluía a sectores sociales emergentes que legitimaban su statu quo por medio de la educación. Algunos de ellos surgieron de esta relación y como parte del contexto de crisis del capitalismo en 1929, que llevó a la propuesta del Estado benefactor de Keynes. Así, en nuestra región se dieron tres tipos de relación entre el Estado y los sindicatos magisteriales (Tiramonti, 2001):

- La creación de sindicatos magisteriales relacionada con partidos o movimientos políticos que, a través de su red clientelar, incorporaron a los sectores sociales emergentes, como fue el caso de las organizaciones docentes (Venezuela, Costa Rica, México, República Dominicana y El Salvador).

- La creación de sindicatos magisteriales que establecía articulaciones con los partidos políticos, pero que a la vez construían espacios de autonomía para las negociaciones corporativas con el Estado (Chile, Argentina y Colombia).
- Los sindicatos que surgieron fuera de la tutela del Estado y de los partidos políticos desde un lugar de plena oposición (Brasil y Guatemala)

En el contexto colombiano, por ejemplo, las primeras organizaciones sindicales del magisterio surgieron a finales de la década de $1930,{ }^{3}$ motivadas por el Partido Liberal. Según Bocanegra (2008), una de las políticas de la Administración de Alfonso López Pumarejo se centró en la creación de organizaciones sindicales afines a su gobierno. Como parte de esta política, se incentivó el reconocimiento de cuarenta pesos mensuales de salario mínimo para los maestros inscritos en el escalafón nacional, así como garantías de seguridad laboral. Años más tarde, se constituyó uno de los sindicatos docentes de mayor envergadura: la Federación Colombiana de Educadores (Fecode), fundada en $1958^{4}$, y ASOINCA nació en 1939, siendo uno de los más antiguos del país, en un momento que coincide con el nacimiento de los sindicatos magisteriales en el continente, pues de acuerdo con Espinola y Accioly (2007) estas organizaciones nacieron entre las décadas de 1930 y 1950.

Ahora bien, los sindicatos en general, y en particular los magisteriales, son conocidos por sus acciones públicas de movilización, en las cuales hacen demandas ante el Estado o visibilizando así sus inconformidades. La movilización es un elemento central de su vida, lo cual se corrobora porque a lo largo de Latinoamérica, maestros de varios países han sido los actores principales de grandes movilizaciones que salen a la calle por varias

3 El primer sindicato de maestros constituido y reconocido legalmente, de acuerdo con Bocanegra (2008), fue la Asociación de Educadores de Cundinamarca, creado en 1938; un año después nació ASOINCA.

4 Las organizaciones que concurrieron a la fundación de la Federación Nacional de Educadores fueron: la Asociación de Institutores de Armenia, fundada en 1945; Asociación Nacional de Profesores de Educación Física, fundada en 1944; Asociación de Educadores del Atlántico, fundada en 1946; Sociedad de Educadores del Magdalena, fundada en 1949; Asociación Distrital de Educadores, fundada en 1957; Sindicato de Maestros de Cundinamarca, fundado en 1938; Asociación de Maestros de Bolívar, fundada en 1945; Centro Nacional de Educadores del Valle, fundado en 1950; Sindicato de Maestros del Tolima, fundado en 1942; Asociación de Institutores del Cauca y el Centro Nacional de Educadores Caldenses, fundado en 1949. (Pulido, 2008, pp. 26-27) 
razones: exigir mayores recursos de inversión para la educación (como es el caso de Colombia, Panamá, Uruguay, El Salvador); mejorar las dotaciones de los centros escolares (Colombia, Guatemala, Panamá, Argentina y Bolivia); exigir la libertad de compañeros presos políticos (México); mejoras laborales (México, Colombia, Guatemala, Honduras, Argentina, Bolivia, Perú y El Salvador); reclamar que bajen los precios en servicios públicos (Guatemala). También se manifiestan porque están en contra de reformas educativas (México, Colombia, Chile, Costa Rica, Bolivia, Perú, Uruguay y El Salvador), de las evaluaciones sancionatorias (México, Colombia y Perú), de reformas pensionales (Brasil) y del asesinato de maestros (México), entre otras.

Es decir, en Latinoamérica las movilizaciones magisteriales se presentan como una expresión pública de inconformidad, demanda y exigencia de los maestros, y han estado auspiciadas, cuando no lideradas, por los sindicatos a los que están afiliados los docentes en sus respectivos países. Estas movilizaciones visibilizan las luchas magisteriales y muestran la fuerza del sindicalismo a la sociedad en general, y en particular al Estado, que es su "oponente" y el actor principal de sus demandas.

Precisamente, lo que muestran la mayoría de las movilizaciones y también de investigaciones sobre el sindicalismo docente, es que en la región latinoamericana los principales actores involucrados en la acción sindical son los maestros organizados y el Estado. ${ }^{5}$ Esta relación es histórica, no solo porque el origen sindical se explica como parte de las dinámicas económicas y sociales de los países de la región, y su vínculo con los partidos políticos que tenían o querían el control del Estado, sino porque los sistemas educativos se configuraron desde políticas nacionales que se viabilizaban por medio de la enseñanza, por lo que los maestros fueron vinculados como trabajadores del Estado.

5 Esta misma relación se puede consultar en Centro de Estudios en Políticas Públicas (cEPP) (2008), Espinola y Accioli (2007) y Tiramonti (2001).
Las movilizaciones magisteriales en la actualidad tienen como contexto fundamental las contrarreformas educativas, que han tenido fuertes impactos en los sistemas educativos de la región. Este objeto de disputa ha llevado a múltiples luchas magisteriales, ya sea por las reivindicaciones gremiales o por la precarización del sistema educativo, o ambas. Para Tiramonti (2001), los sindicatos, y en general el cuerpo docente, ven en las reformas tendencias privatizadoras de la educación pública, ven en la evaluación docente dispositivos de control sobre los profesores, los estudiantes y las instituciones, $\mathrm{y}$ además ven cómo el ajuste presupuestal disminuye los recursos para la educación.

Las reformas educativas han sido las dispuestas para acomodar la educación a los intereses del mercado. Por esta razón, tienen, explícita o implícitamente, objetivos sobre la calidad, la eficiencia y la equidad de la educación, que de acuerdo con Pablo Gentilli et al. (2004) se han convertido en "lemas que atienden a un contexto coyuntural, a la 'globalización neoliberal"'; a las políticas de "ajuste estructural" y/o de control/reducción del gasto público implementadas por los gobiernos; a la redefinición del rol del Estado como garante de los derechos sociales (entre ellos, el derecho a una educación de calidad para todos); y a los procesos de privatización y mercantilización de la educación. Así, la confrontación del sindicalismo magisterial con el Estado no se puede entender por fuera del conflicto social en el que se expresan las crisis económicas, las violencias sociopolíticas y las afecciones propias de cada contexto histórico-espacial. Con la implementación del neoliberalismo en la región, la conflictividad en el sector estatal, particularmente en la educación, es muy significativa.

Las reivindicaciones tanto gremiales como educativas (profesionales, al decir de Loyo, 2008) son exigidas a los entes gubernamentales, pues el Estado es tanto el garante de la educación como el responsable de las vinculaciones y empleador de la mayoría de los maestros en el continente. Las luchas de los docentes tienen que ver principalmente con demandas por mejoras salariales, laborales y 
reivindicaciones educativas, es decir, preservar la educación como derecho.

Frente a las movilizaciones alrededor de las luchas gremiales y laborales, se encuentra que estas se presentan por la falta de incentivos y estímulos económicos para los docentes, por el cumplimiento o la mejora de los estatutos y normas que regulan el ejercicio de esta profesión (Gentilli et al., 2004). Pero también por la condición docente y la exigencia de su dignificación (Rodríguez y Peñuela, 2008).

Históricamente, los conflictos estaban más en el orden de las condiciones laborales que tenían y tienen que enfrentar los docentes, por mejorar sus salarios, sus sistemas de seguridad social y su permanencia. En la actualidad, las reformas para ascenso en el escalafón docente cambian la antigüedad por un sistema meritocrático mediado por evaluaciones sancionatorias, razones que se han hecho evidentes en la movilización magisterial en los últimos años. La política de evaluación docente se comenzó a implementar en varios países (Colombia, México y Perú) y ello ha sido una causa para que los maestros se movilicen y muestren "una significativa capacidad para interferir o detener diversos dispositivos críticos de los procesos de reforma en cada país" (Espinola y Accioly, 2007, p. 8), y propongan otras formas de evaluar la idoneidad profesional.

Frente a las luchas educativas de los sindicatos, estas se dan por las políticas implementadas o propuestas para el sistema educativo. Los sindicatos magisteriales han tomado como bandera la exigencia por un mayor presupuesto para la educación y la defensa de la educación pública, de manera que la ciudadanía pueda mantener su derecho legítimo a educarse, especialmente la que accede a las instituciones públicas. Al respecto, Loyo (2008) encuentra que las principales banderas de lucha de la organización docente en América Latina son: la defensa de la escuela pública y la exigencia al Estado para que cumpla con sus obligaciones en materia educativa, la lucha contra cualquier medida en que se perciba un sentido privatizador, la denuncia constante sobre el carácter excluyente de las políticas neoliberales, la inclusión de los temas de la globalización y del papel de los organismos internacionales, y la participación docente en la formulación de las políticas educativas.

Se trata, entonces, de dos asuntos que provocan las movilizaciones: las luchas gremiales y las políticas educativas. Estas dos causas de confrontación de los sindicatos magisteriales con el Estado no son necesariamente dos tipos y formas de exigencia, más bien se trata de dos asuntos que movilizan el sector y que se relacionan estrechamente por el contexto neoliberal que se implementó en toda la región y que dio lugar a reformas que afectaron tanto los sistemas educativos como la contratación docente.

Existe una crítica al sindicalismo magisterial en general, por limitarse a la lucha gremial propiamente y romper el vínculo que construyó con las bases. Ello tiene que ver, según el CEPP (2008), con que, al defender los derechos laborales de los docentes, se han embotellado en unas estructuras rígidas que no permiten el ingreso de otras formas de pensar el sindicalismo. La misma naturaleza de la organización sindical pareciera ser su propia condena, pues nace para defender los derechos gremiales y esto es, justamente, lo que tiene menos niveles de realización hoy. La acción sindical en la actualidad no logra neutralizar los problemas de exclusión que enfrentan los afiliados, y es allí donde se encuentra una fractura y pierden su sentido, lo que provoca una crisis tanto con su gremio como con el Estado.

\section{Los proyectos colectivos como parte de la identidad del sindicato magisterial}

Los sindicatos magisteriales tienen décadas de existencia, y algunos están a dos décadas de cumplir un siglo de vida. Por lo menos en Colombia, su emergencia se dio a mediados del siglo $\mathrm{xx}, \mathrm{y}$, como se mencionó, Asoinca es uno de los más antiguos (1939). Este sindicato nació de la mano de sectores políticos hegemónicos del Cauca y con sus partidos tradicionales. En el periódico del sindicato se recuerda que estuvo "permeado por la politiquería y más cuando eran los politiqueros de turno quienes daban el aval para trasladar un docente, así ataron el gremio a la politiquería" (70 años de lucha y resistencia [2009], p. 8). Pero con el tiempo fueron 
integrándose distintos sectores políticos e ideológicos de izquierda, que plantearon la necesidad de autonomía frente al Estado y lucharon por el estatuto docente para que los maestros tuvieran garantías laborales en su ejercicio.

En este proceso, Popayán sufrió el terremoto de 1983, uno de los más fuertes del país y que cambió el rumbo de los habitantes de la ciudad y de asoinca. El sismo dejó muchos damnificados, entre ellos docentes que no tenían dónde habitar. Así que algunos maestros sindicalizados decidieron que las ayudas económicas que les llegaban no se entregarían totalmente en dinero, sino que comprarían un terreno para construir las casas de los maestros damnificados. Hoy es Villa Docente, uno de los barrios más reconocidos en la ciudad. Un profesor de aquel momento recuerda:

Los compañeros de los otros departamentos, por medio de la Federación, decretaron un día de salario para solidarizarse con lo del terremoto [...]. En ese tiempo llegó una solidaridad como de 20 millones, entonces el problema que surgía era ¿A quién se le manda esa plata? Nosotros siempre hemos tenido la duda de la corrupción [...] y aquí la cooperativa estaba en quiebra. Ahí surgió la idea de organizar un ente institucional, cooperativa, asociación, inicialmente para poder recibir el aporte nacional y darles a los docentes damnificados [...]. Se pensó en un lote, vino un señor y nos ofreció un lote donde queda "Villa docente" para 38 viviendas y unos apartamentos y organizar el barrio "Villa docente" desde la minga con nuestras familias. Después la gente vio que era real se fue afiliando más y querían ser parte del barrio y fueron haciendo sus aportes en el "fondo de vivienda" dentro de Provitec. (Ángel Navia, comunicación personal, 2017)

En medio de esta tragedia, la organización de maestros creó Provivienda para los Trabajadores de la Educación del Cauca (Provitec), que pasó a ser la cooperativa de Asoinca. Se trató de un trabajo colectivo para la solución de vivienda. Fernando Vargas (comunicación personal, 2017) recuerda que fue un ejercicio de economía popular y allí se fueron generando liderazgos nuevos. Estas personas veían que existían serios problemas con el manejo de los recursos por parte de la Junta Directiva del sindicato, lo que estaba llevando a una desafiliación masiva de maestros; con el pasar de los años, esta "nueva generación" asumió un liderazgo importante y llegó a dirigir ASOINCA.

Los maestros que estuvieron al frente de la construcción de vivienda decidieron disputar la Junta Directiva. Para 1994 obtuvieron cuatro de los diez escaños, y para 1996 lograron equiparar las fuerzas en la junta y comenzaron un proceso de reestructuración interna, no sin disputas con los antiguos líderes. Los sectores políticos e ideológicos que constituían la Junta Directiva se enfrentaron, hasta que las disputas internas llevaron a una fractura del sindicato, y se creó el Sindicato Unitario de Trabajadores de la Educación del Cauca (Sutec), como organización paralela.

En la memoria colectiva sobre la historia reciente de la Asociación, sus lideres y activistas ubican unas transformaciones y rasgos distintivos del sindicato que lo apartan del sindicalismo tradicional. De acuerdo con Burbano (2018), durante la década de los noventa se cuestionó la corrupcion de la organización sindical, expresada en el mal manejo de los recursos, las alianzas con los partidos políticos tradicionales asociadas a los gastos para apoyar las candidaturas electorales o a corporaciones. Se propuso entonces una ruptura con estas prácticas sindicales y en 1996, en las elecciones de Junta Directiva de ASOINCA, una nueva mirada del sindicalismo ganó la presidencia, vicepresidencia, fiscalía y secretaría general, para empezar a erradicar las prácticas sindicales sustentadas en el tráfico de influencias, la ampliación de las burocracias, el favorecimiento obtenido a través de viáticos y bonificaciones. Según el actual presidente de AsoincA,

ningún líder debe tener sobresueldos ni bonificaciones, eso es lo que hace que la confederación fracase, porque los líderes empiezan a manipular a su favor. Líder que cobre, no sirve; tarde que temprano, traiciona, porque lo lleva el interés económico, y no el verdadero sentido de contribuir a combatir el capitalismo. (Vargas y Burbano, Asamblea General, 2018) 
Los cambios en estas prácticas sindicales lograron la ampliación de las afiliaciones. Asornca llegó a completar el $90 \%$ de los maestros del Cauca a inicios del nuevo siglo, lo cual es un indicativo de la credibilidad en el nuevo sindicato.

Las medidas de transformación de la práctica sindical fueron: erradicar errores como sobresueldos, terminar con los viáticos exagerados y los autocréditos; no utilizar los recursos económicos para campañas proselitistas [...]. Lo primero fue recuperar la huelga como principio político, segundo ampliar el periodo de la junta de dos a cuatro años, manteniéndose la reelección, aprobar la posición antielectoral para cargos del Estado y, tercero, reglamentar el uso correcto de los recursos económicos de Asoinca. (Burbano Collazos, 2018, p. 81)

A ello se suma que se amplió la razón de ser del sindicato, que no solo acogería a institutores (docentes), sino también a trabajadores de la educación, conservando su acrónimo. Durante más de dos décadas se han mantenido estas convicciones, bajo una ética de "darle a cada quien según su trabajo y a cada cual según la necesidad", principio capaz de garantizar la vida digna y la supervivencia del ser humano desde una economía solidaria que implica el compromiso y bien colectivo, contrario a la economía capitalista (Provitec, 2016). Así, en suma, se trata de un sindicato que reivindica la lucha de clases, contra la economía capitalista y a favor de la economía popular.

la alternativa es ir construyendo un modelo popular con principios proletarios y por eso [...] tenemos cuatro ejes: el eje de derecho a la educación -está ahí el compañero Miguel Andrés-; el eje laboral - que están otros dos compañeros(sic); el eje de economía popular, que ahí estoy involucrado e intentando ayudar, y el otro eje es de coordinación con movimientos populares. (Fernando Vargas, comunicación personal, 2017)

Esta identidad de clase, se recoge en el horizonte del accionar de su lucha, que se configura desde una propuesta que está en la búsqueda de igualdad de oportunidades, de erradicar la discriminación y de construir una educación basada en la formación para la vida y para el liderazgo popular. Por estas apuestas, el sindicato está en contra de las políticas que rompen con la igualdad de oportunidades, como es el caso de "las pruebas del Icfes que discrimina, selecciona y elitiza [sic] el derecho a la educación universitaria" (El Educador Caucano, 2003, p. 10). La lucha de clases se convierte en premisa para los educadores y trabajadores de la educación; esta posibilita concretar la propuesta pedagógica porque se considera "la clave para saber y entender qué tipo de pedagogía es la que necesita la clase obrera y los sectores populares y la que el maestro consciente debe materializar en su trabajo" (El Educador Caucano, 2003, p. 10).

Estos idearios sindicales junto con los alcances de Provitec, muestran la importancia de la economía popular como forma de confrontar al capitalismo y "la recuperación de la confianza de las bases en este tipo de organizaciones" (AsoINCA, 2018). Desde está lógica, se integra la economía popular al sindicato, que inicia acciones económicas para sus afiliados.

Primero tenemos Villa Docente; luego, en las Américas y se diseñó ese proyecto con la compañía Carvajal [...]. Luego tuvimos la Cristina, que era una proyecto ya casi hecho que nos vendieron; luego compramos otro proyecto, que es Bello Horizonte, ahí son 24 viviendas; y en ese periodo también se compró otro lote grande, a las afueras de la cuidad, un proyecto de los Alpes [...] y fue la primera parcelación de 1000 metros y se pudo dividir en 96 parcelas, hacer una casita y cultivamos (porque yo tengo mi casa allí) y es una vía que conecta con la [vía] Panamericana. (Ángel Navia, comunicación personal, 2017)

Además de las soluciones de vivienda, cuentan con proyectos de economía popular, desde la construcción de un supermercado con productos a buen costo y con ganancias compartidas para sus afiliados según sus compras anuales; bombas de gasolina que ofrecen descuento para los maestros; casa de paso para los afiliados, donde se pueden hospedar los maestros que llegan de otros municipios para hacer algún trámite en Popayán. También se han adquirido terrenos denominados parcelas 
para vivienda y cultivo, edificios de apartamentos, lugares de recreación, entre otros espacios que son organizados por ASOINCA y atendidos por maestros activistas para el beneficio de todos.

Estas acciones, han generado un vínculo muy fuerte y una identidad importante con el sindicato por parte de sus afiliados, pues independientemente de que los maestros sean o no de Popayán, tengan una identidad cultural arraigada como campesinos, indígenas, afrodescendientes o citadinos, cuando se les pregunta por su afiliación a AsoINCA muestran compromiso y orgullo de pertenecer a este sindicato. Los afiliados se refieren especialmente al trabajo colectivo, responsable y ético que ha llevado a la consolidación de la cooperativa y de su sindicato. Precisamente, el posicionamiento de la economía popular ha estado precedido por principios ético-políticos, como la máxima de que el bien colectivo debe estar por encima del individual; el liderazgo se da por el compromiso, la disciplina y la honradez en el trabajo; y los intereses económicos son para el bien colectivo y la solidaridad.

Así, desde la economía popular se le hace frente a la económica capitalista, aunque estando inmersa en ella, pues esta regula el Estado liberal. Sin embargo, les ha permitido disminuir la explotación y la usura de los bancos y las constructoras. Se podría decir que la economía popular "está pensada por y para los sectores populares, que a diferencia de los modelos liberales buscan garantizar la utilización de su propia fuerza de trabajo, como de los recursos disponibles, la satisfacción de las necesidades básicas a nivel material como inmaterial" (Herrán, 2013, p. 36), pero, a la vez, se convierte en un ejercicio político de organización colectiva y de apuesta de otras formas de estar en el mundo.

Más que una concepción única, es una práctica popular que está en el adentro y afuera, porque a la vez que se basa en su normatividad liberal contribuye a la construcción de otras prácticas solidarias desde la economía popular. Para Provitec (2016), la economía popular es la posibilidad de demostrar que existe otra forma de orientar y ejercer el trabajo, que es posible formar miles y miles de personas, desde las mismas entrañas del capitalismo, para destruirlo y crear bases para construir un nuevo sistema de vida.

\section{Apuestas político-pedagógicas desde la educación popular}

AsorNCA desde sus apuestas sindicales establece una relación necesaria entre la formación pedagógica y la política, de allí que sus principios sindicales sean a la vez principios políticos y pedagógicos, en los que se identifica una postura emancipadora y comprometida con las realidades sociales caucanas. Esta perspectiva pedagógica esta referenciada en la historia reciente del sindicato, especialmente asociada a la necesidad de transformar las prácticas y vicios políticos que encarnaba esta estructura, así como a su apuesta por transformar las condiciones de vida de los maestros afiliados y de las poblaciones en las que inciden desde el trabajo educativo.

$\mathrm{Al}$ indagar por cómo inicia, o por qué se asocia la perspectiva pedagógica del sindicato con la educación popular, encontramos que en el 2008 la Junta Directiva empezó a preguntarse cómo hacer procesos formativos docentes que incidieran en la transformación educativa. Así nació la idea de realizar diálogos con quienes son reconocidos en el campo de la educacion popular en Colombia y América Latina:

Y alguien dijo: ¿y mejor por qué no traer a alguien?, y entonces fue cuando apareció Marco Raúl Mejía [...], y así fuimos trayendo gente, y esa gente nos comenzó a posicionar en el fundamento de la educación popular en 2008. Entonces cuando ya nosotros cogemos con Marco Raúl, ya luego viene Alfonso [Torres], viene Lola [Cendales], viene Alfredo [Ghiso], entonces entre el 2010 y 2013 este colectivo se consolida con el grupo de Educación Popular de la Universidad del Cauca. (Burbano, Taller con el Colectivo de Educación popular, 2017)

La lectura de Freire a partir de dialéctica de opresores-oprimidos y la educación bancaria frente a la educación para la liberación es fuente de debate 
en el colectivo. Asimismo, la lectura crítica de la realidad y el análisis del despertar de la conciencia comenzaron a atravesar gran parte de las reflexiones y propuestas formativas lideradas por AsoINCA. La Pedagogía del oprimido (1984) y su crítica a la educación bancaria, entendida así por depositar en el estudiante a manera de inventario contenidos sin sentido y acríticos, ocultando las razones de cómo están siendo los hombres y mujeres en el mundo, se discute al ser negadora de la posibilidad del diálogo y la libertad.

Precisamente, AsoINCA fortaleció la discusión y el análisis acerca de los principios y acciones que le posibiliten construir una concepción que diera soporte a su trabajo educativo popular. En ese sentido, con la anuencia de la educación popular, consideraron "necesario replantear, reformular la cotidianidad, desmenuzar la rutinización y aportar en la construcción de una educación popular concebida como un proceso que lleva desde la práctica y su realidad a reedificar los comportamientos" (El Educador Caucano, 2012). Para AsoincA, se hizo necesario que los colectivos docentes construyeran prácticas encaminadas hacia una educación liberadora, en el sentido de dar por hecho que "El educador puede liderar solo si es libre, una educación popular es posible, solo si las personas nos reconocemos como explotados, es un deber político ser un educador popular y en ello dignificar la vida de los pueblos" (El Educador Caucano, 2012, p. 7).

La educación popular se convierte en fuente de debate y recontextualización en el escenario educativo caucano. Por esto, también se plantea la necesidad de que el educador popular de Asoinca asuma como suyas prácticas antagónicas al individualismo, al consumismo, al hedonismo y a la corrupción, que son criterios centrales del sindicato.

Este proceso se constituyó para los docentes en un espacio vital a nivel formativo donde se encontraban y reflexionaban sobre sus prácticas y proyectos. La educación indaga por las dificultades y necesidades de los profesores en el desarrollo de sus prácticas educativas, lo cual les fue permitiendo fortalecer prácticas colectivas y atender las deman- das pedagógicas de los docentes. A partir de estos encuentros, AsoINCA amplía su mirada sindical, y a la lucha reivindicativa le suma una lucha educativa, entendida desde su relación con la política:

Política es toda actividad humana que tiene que ver fundamentalmente con todos los principios con los que yo rijo mi vida. Es decir, todo ser humano es político, nadie es apolítico. Lo que sí debe decidir la persona en su comportamiento humano es si va a ser de la política de los ricos, como dice Lenin, o de la política de los pobres, o como lo plantea Marx, la política del explotador o la política del explotado, en cuál de esos comportamientos voy a vivir. Para Freire se trata de identificar si usted está dentro del oprimido o dentro del opresor, qué clase de comportamiento. Así las cosas, la pedagogía no tiene ninguna diferencia de acto político, la pedagogía es un acto político. (Burbano, Taller con el Colectivo de Educación Popular, 2017)

ASOINCA asume como principios educativos la defensa de la educación pública y popular; el ingreso gratuito al sistema con todas las garantías: transporte, alimentación y útiles; dotación de infraestructuras y equipamiento de las escuelas; y vincular la acción educativa al proceso económico de la comunidad y de la región. Para ello, constantemente se crean espacios donde se analizan los programas, los contenidos y la metodología de la que denominan educación capitalista en perspectiva freireana, con la perspectiva de construir una educación popular contextualizada en el Cauca. Al respecto, en el sindicato se han abierto espacios de formación en educación popular para los maestros, como el Colectivo de Educación Popular, la revista Pensamiento Popular, el periódico El Educador Caucano, talleres de formación con maestros y el Encuentro Internacional de Educación Popular. Estos espacios están conformados por los maestros afiliados al sindicato, algunos de los cuales llevan a cabo experiencias educativas con base en la formación construida en los espacios creados por ASOINCA.

- El Colectivo de Educación Popular. Es un "colectivo de integración política" confor- 
mado por maestros activistas sindicales del departamento que proyectan como eje aportar a los procesos de formación permanente, por eso están a cargo de pensar y proponer la educación popular en el sindicato. Se trata de un espacio educativo de discusión, donde se realizan propuestas para desarrollar con profesores, estudiantes y comunidad educativa en general. Se reúne una vez a la semana.

- Los talleres pedagógicos. Son espacios direccionados por el Colectivo de Educación Popular, en los cuales se hace de la formación popular un proceso permanente de conocimiento $y$ reconocimiento de prácticas y experiencias populares. Son, a la vez, una forma de proyectar y articular los espacios de formación del mes de junio.

- La revista Pensamiento Popular. Así como lo enuncia su primer número, es un medio de formación que la Junta Directiva departamental de Asoinca, el Colectivo de Educadores Populares del Cauca y el grupo de Educación Popular de la Universidad del Cauca materializaron a fin de "canalizar para pensarnos otra educación, otra actividad sindical, es un documento que permite a docentes, padres y madres de familia del Cauca y otras regiones de Colombia dar a conocer sus experiencias en la actividad educativa, sindical y popular" (ASOINCA, 2014a, p. 1). Se publica anualmente.

- El periódico El Educador Caucano. Es el medio de comunicación de asoinca que da a conocer los acontecimientos de la región relacionados con el magisterio del Cauca y del resto del país. Allí, por ejemplo, se dan informes de la Junta Directiva, se denuncian los incumplimientos del Gobierno nacional, pero a la vez se muestran experiencias educativas en el Cauca, o se presentan reflexiones sobre el papel del educador en el momento histórico.

- Semana de la Formación Sindical. Desde 1998 Asoinca logró que la Gobernación del Cauca firmara un acuerdo para que se diera una semana de formación a los maestros del depar- tamento con el objetivo de mejorar la actividad pedagógica y educativa. Esta semana ha sido dirigida por el sindicato y las subdirectivas, ${ }^{6}$ quienes proponen y agencian los programas de formación durante una semana de junio todos los años. Allí se orienta al trabajo de educación popular, formación política o de acuerdo con las necesidades del momento.

- Encuentro Internacional de Educación Popular. Tiene como objetivo generar espacios de reflexión crítica en torno a la educación. Se trata de un espacio de participación, diálogo a partir de reflexiones, prácticas desarrolladas y apuestas políticas que permiten construir procesos de transformación social. En él, se da cabida, entre otros, a intelectuales populares, maestros, organizaciones sociales y estudiantes para conocer y debatir en torno a la educación emancipadora.

- El vínculo con la Maestría en Educación Popular de la Universidad del Cauca. Desde el 2012, el Colectivo de Educación popular y el grupo de investigación en Educación Popular de la Universidad del Cauca decidieron articularse para proponer una maestría para los maestros del departamento. Así se dio origen a la Maestría en Educación Popular, a la cual han ingresado varios docentes afiliados a ASOINCA, que tienen experiencias de trabajo pedagógico en la escuela.

Desde estas prácticas concretas, además de las movilizaciones, huelgas, denuncias y otras acciones propias del sindicalismo magisterial, se sostiene el principio de la "defensa de la educación pública y popular", que además encontramos en las experiencias pedagógicas a lo largo del departamento. Por eso, aquí consideramos importante mostrar la manera en que Asoinca viabiliza la formación político-pedagógica con los maestros, quienes son

6 Las subdirectivas forman parte de la estructura de ASoINCA y son la forma organizativa del sindicato en cada municipio. Se encargan de liderar las políticas del sindicato a nivel regional, pero todo eso está orientado por la instancia máxima, que es la Asamblea General de Delegados. 
reconocidos como profesionales de la educación sindicalizados.

Un ejemplo importante es la incidencia de la Semana de Formación Sindical en los maestros del departamento, pues este espacio, creado para fortalecer el trabajo pedagógico y político desde la educación popular, les permite interactuar con sus colegas a partir de reflexiones y comprensiones de las prácticas educativas que se realizan en las escuelas. Esta la consideran como parte de su formación, tal como lo expone la profesora Sara Jiménez:

Aquí se han traído docentes de departamentos a que hagan presentaciones de sus experiencias significativas, experiencias pedagógicas, de educación popular, nos han dado orientación en la parte de la nutrición. Es decir, en todos los aspectos nos dan formación, no son cursitos, es formación en la parte pedagógica, ese ha sido una ganancia para todos [...]. Nos han dado muchos lineamientos de cómo hacer una educación alternativa, de alimentación sin tanta contaminación. (Comunicación personal, marzo del 2017)

Aquí surge un interrogante sobre las prácticas que se realizan, y cómo estas nuevas experiencias de los colegas pueden adelantarse en otras instituciones. De la mano de la Semana de Formación, se articulan las agendas de los espacios formativos para desarrollar el Encuentro Internacional de Educación Popular, el cual se realiza cada dos años y ha contado con la participación de académicos de reconocida trayectoria no solo de Colombia sino de otros países de América Latina. El hecho de que los maestros escuchen e interactúen con los "intelectuales" que han venido leyendo y oyendo, los convoca a pensar su práctica educativa de manera más sistemática:

Me interesaba muchísimo cómo AsoINCA traía a esas personas, como Alfredo Ghiso, Marco Raúl, yo decía bueno un sindicato que se piense una formación pedagógica con estos personajes, qué bueno. Me comenzó a atraer un poco más a ASoinca [...], me fui interesando y ya no solamente fue ser un espectador yo creo, sino en participar en algunas acciones importantes. De esa manera, en 2015 y en 2016 el profe Miguel nos invitó a participar en el Colectivo de Educación
Popular y fue sumamente interesante, el gancho por el cual yo también ingresé fue la parte de investigación, esa es una de las cosas que me gusta y que he leído mucho, qué interesante que también un sindicato se piense desde la investigación, desde escribir, sistematizar, desarrollar otras prácticas. Desde 2015 logré entender esa relación entre los principios políticos con la pedagogía, qué tanto puedo hacer yo desde mi aula de clase, desde mi institución educativa para desarrollar otros procesos en beneficio de todos, moviéndonos siempre por uno de los principios de Asoinca que es la solidaridad. (Maritza Córdoba, comunicación personal, 2017)

La participación en espacios formativos logra, en algunos casos, afectar la subjetividad del docente, quien se cuestiona y se compromete con su labor desde perspectivas político-educativas que permitan incidir en la escuela. En la referencia de la profesora, se ve cómo la participación en un encuentro, más una invitación a formar parte de un grupo de maestros, va cambiando la mirada del sindicato, pero a la vez la mirada sobre la investigación y la educación, pues se genera un compromiso profundo con la profesión docente. En ese sentido, se reconocen los aportes de quienes han liderado la educación popular en nuestro país y que motivaron la constitución del Colectivo de Educación Popular de asoinca.

El sindicato también posibilitó la formación de maestros desde la Maestría en Educación Popular de la Universidad del Cauca. Se trata de un proceso de educación formal que expresa cómo las perspectivas y posiciones políticas y pedagógicas de AsoINCA han llegado a incidir en la educación superior, no solo por el apoyo en la creación de la maestría, sino con el ingreso de maestros a ella. Allí, los profesores encuentran la posibilidad de confrontar el papel que se le ha otorgado a la educación con las necesidades reales de los contextos socioeducativos; asimismo pueden recobrar o dar mayor sentido al papel del docente en dicho proceso. En palabras de una profesora:

En el 2013 también, el estar en la maestría y trabajar sobre los sentidos para comenzar a develar todo eso que desconocíamos. Y la maestría nos 
acercó más a AsoincA [...]. La maestría hace un trabajo en tratar de develar el papel de la educación, el papel de la formación y cuál es nuestro papel como docentes. (Diva López, comunicación personal, agosto del 2017)

ASOINCA, en los diversos escenarios de formación, ha logrado fortalecer las perspectivas en la educación popular, aspecto que incide en las prácticas y la afección del ejercicio docente desde esta perspectiva emancipadora.

El proceso formativo tiene un fuerte componente político para los educadores. Si bien estos procesos inciden en las posiciones y discursos de los docentes, también lo hacen en sus experiencias pedagógicas. Al respecto, son variadas las experiencias pedagógicas que realizan los maestros en el Cauca y que se han fortalecido con la formación en educación popular que han encontrado en Asoinca. Aquí queremos profundizar en una de las propuestas pedagógico-políticas más fuertes: la soberanía alimentaria.

ASOINCA tiene un colectivo de soberanía alimentaria, al cual están vinculados profesores de varias instituciones del departamento. Algunos de ellos han implementado o fortalecido sus propuestas pedagógicas, como la tienda escolar saludable, las huertas escolares, los proyectos investigativos sobre agroecología, huertas caseras y comunitarias, recuperación de semillas propias, entre otros.

El Colectivo tiene dentro de sus intenciones resignificar la idea de consumo y la siembra como una práctica de fortalecimiento de la identidad de las comunidades y de economía popular. Se articula al principio de ASOINCA de economía popular que enfrenta al modelo económico capitalista para demostrar que hay otras formas de administrar los recursos al dejar de pensar que solo unos pocos se beneficien del trabajo de muchos, y proponer que sean muchos los que se beneficien de su arduo trabajo, o como ellos dicen: "a cada quien según su trabajo".

Tito Torres, actual tesorero de AsoincA (2019) y miembro fundador del colectivo, menciona que en el 2006 inició esta propuesta de soberanía alimentaria con el ánimo de incidir en las prácticas, los valores y la transformación curricular del mundo escolar capitalista. De allí que advierta que la propuesta no puede ser leída como un activismo, sino como un proceso de compresión de la realidad social, ya que:

Tenemos en nuestra escuela padres de familia, estudiantes, docentes, terrenos, restaurante. ¿Qué hacer? Pues construir un currículo para la vida, propuesta de un currículo de acuerdo a la realidad, enseñar y formar para la vida, producir conocimientos con base a la experimentación científica, crear autonomía en la producción, distribución y consumo, la huerta. (Tito Torres, comunicación personal, agosto del 2017)

Este proceso implica la recuperación de semillas propias, la investigación sobre los recursos naturales y el control biológico, la creación del banco de semillas, entre otros. El Colectivo trabaja para que esta propuesta sea tanto de soberanía como de formación político-pedagógica, y una estrategia de enseñanza de las áreas en las escuelas. En ese sentido, realiza acciones pedagógicas, como visitar las instituciones educativas para exponer los principios de la soberanía alimentaria y animar a los profesores a comenzar sus huertas; socializaciones en la Semana de la Formación sindical o en los encuentros internacionales de educación popular para dar a conocer la labor del colectivo y lo que se hace en las escuelas; encuentros con los profesores que tienen experiencias de soberanía alimentaria. Pero lo más importante es la existencia del colectivo, que funciona como red de apoyo en las escuelas con los profesores y estudiantes, lo cual permite la visita a diferentes instituciones, tanto rurales como urbanas, para fortalecer el proceso de formación de la comunidad educativa.

En la actualidad, este colectivo está integrado por profesores de más o menos veinte instituciones educativas del departamento que enfocan su interés en preservar los recursos de su territorio, en especial los alimentos para consumirlos sanos y limpios. La producción de alimentos posibilita la articulación con las familias y, en algunos casos, con las comunidades, porque ellos replican o compran 
los productos por la confianza y tranquilidad que da el saber que consumen productos limpios. A la vez que se genera un sentimiento de confianza por el especial cuidado con el territorio al cultivar sin transgénicos que afecten el medioambiente y sus cuerpos.

Los procesos de formación pedagógica también se dan en las parcelas, que son los lotes que los maestros han adquirido por medio de la cooperativa de Provitec. Allí, el Colectivo de Soberanía Alimentaria trabaja en la formación de los maestros, por ejemplo a partir del cultivo de semillas, de plantas alimenticias, aromáticas, incluso en la cría de animales como cerdos, vacas, pollos, peces y conejos. Este ejercicio no es solo de producción alimentaria, sino que se convierte en un escenario de formación de profesores y estudiantes, por cuanto estos procesos se pueden replicar en las instituciones escolares donde trabajan los docentes. El profesor Alirio Alegría se refiere así al proceso:

Unos docentes del grupo de soberanía vienen desarrollando trabajos con la comunidad, o en su colegio, o en su escuela, y en la semana pedagógica [...] muestran lo que han hecho, en qué han avanzado. [...] También, ahora viene un trabajo más con las parcelas que tiene el magisterio, ya se les ha venido dando orientación de no únicamente construir en ladrillo las casas, sino trabajar desde lo orgánico. (Comunicación personal, agosto del 2017)

Aunque esto no se logra en todas las parcelas, se ha venido consolidando con algunos profesores. Igualmente, para el fortalecimiento de este proceso formativo, ASOINCA compró un terreno donde el colectivo realiza labores de siembra en el marco de los principios de la soberanía alimentaria. La idea es que este terreno sea trabajado por los profesores en liderazgo del colectivo y sirva como escenario para el aprendizaje de los estudiantes en las diferentes áreas del sistema educativo. A este espacio se le denomina la Huerta Colectiva de Provitec, desde la que se busca

Demostrar a estudiantes y a sus profesores que es posible trabajar con principios de la agricultura organizada. De esta manera, queremos animarlos a establecer o valorar más las huertas escolares, mostrar que es posible superar el concepto de la propiedad privada. Beneficiar a los afiliados del Sindicato con la venta de productos sanos y nutritivos; conservar, difundir e intercambiar cultivos y semillas tradicionales tales como... frijol cacha, papa, cidra, frijol, café, garbanzo además de experiencias de cultura organizada y de vida. (ASOINCA, 2008)

La huerta forma parte del colectivo, y sus miembros programan encuentros para la limpieza de la parcela, la siembra y el cuidado de los alimentos. Esto se hace en tiempos extracurriculares, con la intención de que se convierta en un escenario de aprendizaje y de resistencia alimentaria desde la educación pública y popular.

Un caso puntual de formación de maestros en soberanía alimentaria se encuentra en la Institución Educativa la Tetilla, con maestros que han sido formados en el colectivo. Allí laboran dos docentes que se interesaron en la propuesta y en la actualidad la están agenciando desde la huerta escolar y el reciclaje. La intención, además, es que mientras los estudiantes siembran, aprendan conocimientos de algunas disciplinas escolares y conozcan otras formas de vida y de relacionamiento con la naturaleza.

Ahora bien, el colectivo también ha encontrado una relación muy estrecha con la propuesta de educación propia dirigida por las organizaciones indígenas de la región. Varios maestros de las escuelas de educación propia están afiliados a AsoINCA, y en esa intersección se han encontrado tanto el colectivo como los maestros que propenden por la educación propia, y que también tienen la intención de recuperar los saberes y prácticas - no solo alimentarias - de vida alternativa al modelo capitalista.

En esta intersección y apoyo mancomunado se pueden mencionar las experiencias de soberanía alimentaria abordadas en la Institución Educativa Agropecuaria del resguardo indígena PaletaráCauca, la cual ha sido desarrollada por las comunidades indígenas y está basada en la recuperación de especies nativas para arborizar, la rotación de 
cultivos, la recuperación de especies de consumo tradicionales (papa, cebolla, arracacha, etc.), así como de plantas medicinales (AsoincA, 2008).

Otro proyecto muy interesante es el realizado en la Institución Educativa del Mesón, en el municipio de Morales (Cauca), institución dirigida por las organizaciones indígenas. Allí se adelanta el proyecto agroecológico, encaminado a confrontar los efectos producidos por la construcción de la represa de Salvajina. ${ }^{7}$ Uno de los principales problemas encontrados por los docentes fue la destrucción de los sistemas de producción y consumo alimentario propios. Con base en esta preocupación, los docentes buscaron controvertir la dependencia alimentaria de los habitantes, así como el incremento de los índices de desnutrición. Con este fin, propusieron un proyecto educativo agroecológico que permitiera

el abastecimiento de alimentos y aguas libres de contaminación química. Dentro de las actividades que durante los últimos diez años han realizado están: la recuperación y conservación de las fuentes de agua, con la cual se ha logrado la construcción de acueductos veredales; la recuperación, conservación y producción de semillas autóctonas, con lo cual se ha logrado la recuperación de varias semillas de frijol, cidra, maíz, sisa, rascadera, guayaba, lulo, entre otras; elaboraciones de alimentos con los productos recuperados; la utilización de arcilla para pintar cuadros y la obtención de lana de oveja; la elaboración de proyectos encaminados a mejorar las condiciones de productividad y nutrición de la comunidad en general; organización del mercado agroecológico, organizado [sic] por todos los centros educativos vinculados con este proceso y en donde comparten experiencias, productos, semillas, etc. (ASOINCA, 2018)

7 Con el desarrollo de la represa la Salvajina, los habitantes fueron desplazados de sus predios y aislados de otros municipios debido a la destrucción de caminos, carreteras y puentes que ellos habían construido de manera comunitaria. Después de veinticuatro años de construida la represa, los habitantes siguen esperando la reparación, ampliación de las carreteras y las vías de acceso a la cabecera municipal y a sus veredas, además de esperar que se construyan las fuentes eléctricas y acueductos prometidos por la EPSA para la construcción de la represa (ASOINCA, 2008).
La soberanía alimentaria confronta la producción capitalista, los problemas de desnutrición, la industria agroquímica, el cultivo de transgénicos, el consumismo y la pobreza que viven diversas poblaciones.

También, podemos nombrar las experiencias pedagógicas agenciadas por profesores afiliados y con fuerte vínculo político-pedagógico con AsoINCA, como las propuestas educativas para la preservación del medioambiente; propuestas de lectura y escritura crítica con estudiantes; formación para la paz en niños; fortalecimiento de la identidad y la interculturalidad; proyectos de investigación agropecuaria, entre otros. Estas experiencias surgen de maestros cercanos al sindicato, y lo que hace ASOINCA es apoyar desde los principios pedagógico-políticos a los maestros en procesos de reflexión, sistematización y formación no solo para potenciar el saber disciplinar, sino para propiciar espacios de transformación del pensamiento y la acción pedagógica.

De modo que la apuesta pedagógica de Asoinca que se viabiliza por medio de la propuesta de soberanía alimentaria se configura de varias formas: desde los proyectos directamente planteados y agenciados por el colectivo de soberanía para la formación de maestros; los que son desarrollados en las instituciones con profesores que pertenecen al colectivo; las propuestas en instituciones educativas indígenas con las cuales el sindicato establece sinergias; y los espacios de formación y socialización de experiencias. Todas ellas se sustentan en la transformación de un modelo de consumo, producción y circulación de los bienes que fundamentan la existencia humana priorizando el bien común.

Sin duda, se trata de una perspectiva y práctica vinculante entre pedagogía y política, que ha permitido caminar en la construcción de un sindicalismo diferente. Esta tarea supone recuperar un "proyecto de transformación social aprendiendo con la historia que no hay proyecto sin sujeto. Eso quiere decir políticas de reconocimiento, de dar la voz. Y quiere decir también trabajar con saberes de emancipación, construidos desde la investigación autónoma y crítica" (Martínez Bonafé, 2011, p. 135), tarea que 
el sindicato viene asumiendo de manera comprometida desde la educación popular, materializada en la soberanía alimentaria.

Se trata de un sindicalismo con saberes pedagógicos emancipadores, en el que existe, como lo plantea Do Vale (2001) una relación importante de la pedagogía freireana en la formación sindical docente, basada en una concepción del trabajo educativo con la transformación de la sociedad, en la que la dialéctica de la educación reside en un carácter eminentemente revolucionario de la pedagogía y en el carácter eminentemente pedagógico de la revolución.

\section{Conclusiones}

La inquietud que movilizó esta investigación se centra en ubicar las apuestas pedagógicas agenciadas por el sindicalismo magisterial. Búsqueda ética y política que invita a pensar el sindicalismo magisterial de cara a su labor pedagógica, y que contribuye a la formación de los ciudadanos y a mejorar las condiciones de existencia de maestros, niños, jóvenes y familias.

Desde este lente nos encontramos con ASOINCA, un sindicato que sin desmedro del carácter reivindicativo que históricamente le ha marcado, hace de la pedagogía un lugar para la transformación social, estableciendo un vínculo fuerte en su accionar político con una pedagogía comprometida con la transformación social. Aquí, hay una relación cosupeditada de lo pedagógico con lo reivindicativo gremial, ambas caras de la moneda son constitutivas de la lucha docente. Hay una articulación muy fuerte entre los dos campos que hemos enunciado: el educativo-pedagógico, y el gremial-reivindicativo, juntos atravesados por lo político. Incluso en los discursos de sus líderes no se asumen uno y otro campo como diferenciados porque forman parte de su lucha social.

Sin embargo, en el análisis, como lo plantea Loyo-Brambila:

Podemos discernir en su acción dos lógicas: la gremial y la profesional y, al delimitar los ámbitos en que estas lógicas se despliegan, descubrimos casi siempre que se trata de intersecciones entre el campo político y el campo de la educación. (2008, p. 346)

Por eso, profundizamos en el profesional, pese a que Asoinca le apuesta a esta intersección y se fortalece como organización social y gremial, ya que agrupa y lucha por el mejoramiento de las condiciones laborales de los trabajadores de la educación, al tiempo que reconoce y le apuesta al trabajo colectivo de profesionales de este sector, que transforman sus realidades sociales desde la educación popular.

El puente de estas dos luchas sindicales: lo pedagógico y lo reivindicativo, lo constituye la educación popular, perspectiva asumida por AsoINCA y en la que se hace del ejercicio pedagógico, un lugar de resistencia y re-existencia contra las dominaciones: capitalistas, racistas, sexuales, culturales, entre otras.

Precisamente, desde hace más de una década, el sindicato viene construyendo una educación problematizadora, comprometida con la liberación, con el reconocimiento de la potencia que tiene la educación en la transformación de la realidad. Tanto es así, que en los espacios que ha construido el sindicato ${ }^{8}$ es evidente la apuesta por el diálogo, la reflexión sobre la acción, las propuestas contextualizadas y la relación entre teoría y práctica como acciones fundamentales del proceso formativo y práctico de los docentes, sobre todo desde el ejercicio educativo de la soberanía alimentaria. En estos escenarios, se evidencia que la impronta de la educación popular basada en el diálogo y reconocedora del saber del otro está enraizada en las prácticas sindicales y en los procesos de formación docente, a modo de esperanza y sueño que busca transformar la sociedad a la vez que se transforma la escuela.

Esto muestra también que asoinca lleva a cabo propuestas político-pedagógicas, como la soberanía alimentaria, la economía popular y la educación popular, que le posibilitan salir del rol común y tradicional del sindicalismo magisterial, basado en lo reivindicativo y gremial, y abordar campos que lo vinculan con los afiliados, la escuela y las

8 Véase la sección "Los proyectos colectivos como parte de la identidad del sindicato magisterial". 
organizaciones sociales. El fortalecimiento del trabajo pedagógico lleva al sindicato a crear y recrear conocimientos pedagógico-políticos, en este caso sobre la educación popular, que fortalecen, no solo al sindicato como gremio, sino a los sujetos de la escuela, y en algunos casos de las mismas comunidades y sus vínculos con otras organizaciones.

El abordar una apuesta educativa desde la formación y la práctica pedagógica le posibilitó al sindicato fortalecer sus vínculos con los docentes afiliados, ya que a través de la educación popular los dirigentes llegaron e incidieron en la cotidianidad de estos, de las escuelas, de las comunidades y de las familias; esta cercanía estrechó los vínculos directos y cotidianos entre unos y otros. Se podría decir que estos vínculos recíprocos fortalecen las luchas históricas que tienen que ver con lo gremial, con la defensa de la educación pública y en contra de las políticas neoliberales, porque a la par con el trabajo en educación popular se está en la dinámica de conocer y movilizarse frente a las afecciones de las políticas hacia el magisterio y la educación en general.

Además, llevó a que el profesor encuentre en el sindicato un lugar de referencia pedagógica, de ejemplo educativo y de lucha social que, desde el trabajo colectivo, contribuye al fortalecimiento de la profesión y del gremio docente. El hecho de que el sindicato se vincule a ellos desde un conocimiento pedagógico y político implicó también un reconocimiento profesional de los docentes, de su escuela como el lugar práctico de la teoría que se construye, y de su trabajo como una labor cotidiana fundamental para la transformación.

Estos aspectos son centrales en la identidad, y su reconocimiento ha posibilitado mayor cercanía de los maestros con su sindicato, al tiempo que fortalece los vínculos colectivos. Además, se ha posicionado al sindicato magisterial desde un atributo de su identidad colectiva y desde su diferencia con los otros sindicatos: la profesión docente.

ASOINCA desarrolla líneas de acción que están vinculadas directamente con la formación docente que involucra a las escuelas, las familias y la comu- nidad. Este aspecto implica una relación fuerte entre la labor sindical y la formación de sus afiliados, que parte de reconocer que

el acto de formación del docente emancipador es un acto voluntario que va más allá del ascenso salarial; esta formación docente tiene que ver con el contexto cultural, político, económico e ideológico, pero, sobre todo, con la toma de decisión de los individuos. En esta formación interviene el sitio donde viven, el lugar donde trabajan, la relación entre su contexto, sus necesidades y la coyuntura social. (Burbano, 2018, p. 95)

Ello indica que el sindicato está en la labor diaria del maestro, en su aula y su comunidad; no solo es visible cuando se sale a la calle a luchar por sus justas causas reivindicativas y gremiales, sino que es vida en sus estudiantes y su contexto. Allí se implementan los proyectos educativos que construyen los propios maestros con algún tipo de vínculo y apoyo de ASOINCA. Así, el maestro se siente como tal, porque vincula su quehacer profesional, que le da sentido a la existencia, con la organización que contribuye a su formación y crecimiento.

Precisamente existen varias lecturas sobre el sindicalismo, y, específicamente, sobre la situación del sindicalismo magisterial. Lo que quisimos mostrar es que existen sindicatos docentes, que a la vez que realizan sus reivindicaciones gremiales como trabajadores, le apuestan al fortalecimiento de su campo profesional: la educación. Esto los fortalece como sindicato, y en lugar de crisis, encontramos que viven momentos de fortalecimiento en sus luchas y propuestas.

\section{Referencias}

Asociación de Institutores y Trabajadores de la Educación del Cauca. (ASOINCA). (2014a). Editorial. Revista Pensamiento popular, 1, 9-10.

Asociación de Institutores y Trabajadores de la Educación del Cauca (ASOINCA). (2014b). Colectivo de Soberanía Alimentaria. Educación popular y escuela: Agricultura urbana, una experiencia de educación popular desde la soberanía alimentaria. Revista de Pensamiento Popular, 1. 
Asociación de Institutores y Trabajadores de la Educación del Cauca (ASOINCA). Junta Directiva (2018). El conflicto entre el comité ejecutivo de Fecode y la Junta Directiva de ASOINCA ... No es de carácter económico, es político [comunicado].

Asociación de Institutores y Trabajadores de la Educación del Cauca (ASOINCA). (Junio del 2008). Experiencias pedagógicas agropecuarias [video]. Departamento de Comunicaciones de ASOINCA.

Asociación de Institutores y Trabajadores de la Educación del Cauca (AsoincA). (s. f.). Colectivo de Educación Popular Asociación de Institutores y Trabajadores de la Educación del Cauca. Segundo eje de trabajo AsoINCA. Defensa de la educación pública y popular, derecho a la educación.

Bocanegra Acosta, H. (2008). Magisterio colombiano: Organización sindical y actor político. Antecedentes históricos, 1934-1958. Diálogo de Saberes, 29. 35-60.

Burbano Collazos, M. Á. (2018). Aportes de la formación docente coordinada por ASOINCA en la actividad sindical y sus procesos organizativos. [Tesis de maestría, Universidad del Cauca]. Repositorio institucional Unicauca http://repositorio.unicauca.edu.co:8080/ handle/123456789/1176

Centro de Estudios en Políticas Públicas (CEPP) (2008). Los sindicatos docentes en América Latina. https:// www.kas.de/c/document_library/get_file?uui$\mathrm{d}=13 \mathrm{ea} 84 \mathrm{db}$-af30-d2d1-de4f-c639660ade2b\&groupId $=252038$

Colectivo de Educadores Populares del Cauca. (2014). El Colectivo de Educadores del Cauca: La construcción de un camino político para la transformación social y educativa. Revista de Pensamiento Popular, 1.

Do Vale, A. (2001). A influência da pedagogia Freirana na formação sindical docente. En C. A. Torres (comp.), Paulo Freire y la agenda de la educación latinoamericana en el siglo XXI. Clacso.

Espinola, V. y Accioli, A. C. (Eds.). (2007). Sindicalismo docente y reforma educativa. Banco Interamericano de Desarrollo.

Euscátegui Pachón, R. A. (2015). El Colectivo de Educadores del Cauca: Perspectiva para una educación popular desde la región. Pensamiento Popular, 2, 24-27.

Freire, P. (1984). Pedagogía del oprimido (34. ${ }^{\text {a }}$ ed.). Siglo xxI Editores.
Gentilli, P., Suárez, D., Stubrin, F. y Gindín, J. (2004). Reforma educativa y luchas docentes en América Latina. Educ. Soc. Campinas, 25(89), 1251-1274.

González, M. I., Aguilera Morales, A., Rodríguez, V. y Torres, A. (2017). Informe final de investigación "Experiencias pedagógicas para tramitar el conflicto en contextos de guerra: Propuestas desde los sindicatos magisteriales" (DSI 454-17). Centro de Investigaciones de la Universidad Pedagógica Nacional.

González Terreros, M. I., Aguilera Morales, A. y Torres Carrillo, A. (2014). Investigar subjetividades y formación de sujetos en y con organizaciones y movimientos sociales. En C. P. Echandía, A. Díaz Gómez y P. Vommaro (comps.), Acercamientos metodológicos a la subjetivación política: debates latinoamericanos (pp. 49-70). Clacso-Universidad Distrital Francisco José de Caldas.

Herrán Gómez, J. (2013). La economía popular y solidaria: Una práctica más que un concepto. Retos, 3(5), 35-42.

Loyo-Brambila, A. (2008). Sindicalismo magisterial. Revista Mexicana de Investigación Educativa, 13(37), 345-349.

Martínez Bonafé, J. (2011, julio-agosto). Sindicalismo y renovación pedagógica. El Cotidiano, $n .^{\circ} 168$, 127-136.

Provivienda para los Trabajadores de la Educación del Cauca (Provitec). (2016). Provitec: Construyendo economía y poder popular. ASOINCA.

Pulido C., O. (2008). La Federación Colombiana de Educadores (Fecode) y la lucha por el derecho a la educación: El Estatuto Docente. Laboratorio de Políticas Públicas-Flape.

Rodríguez, V. M. y Peñuela, D. (2008). La cuestión docente: Colombia, los estatutos docentes. Flape.

70 años de lucha y resistencia. (2009, julio-agosto). El Educador Caucano, n. ${ }^{\circ} 28$.

Tiramonti, G. (2001). Sindicalismo docente y reforma educativa en América Latina de los '90. Flacso-Preal. 
